\title{
Adaptation and validation of the Argentine version of an instrument to assess continuing professional development activities
}

\author{
Laura Fraguas, M.D. ${ }^{a}$, Valeria Vietto, M.D. ${ }^{a}$, Dolores Arceo, Master ${ }^{a}$, \\ Fernando Vázquez Peña, M.D. ${ }^{a}$ and Eduardo Durante, M.D. ${ }^{a}$
}

\begin{abstract}
Introduction. Canadian researchers developed a self-administered questionnaire to ask participants of continuing professional development (CPD) activities about their intention to translate the knowledge acquired in the classroom into clinical practice. The questionnairemay facilitatequality improvement processes in such CPD activities.

Objective. To translate, cross-culturally adapt and validate the original English REACTION questionnaire (A theoRy-basEd instrument to assess the impACT of continuing professional development activities on professionalbehavIOr chaNge) for its use in Argentina.

Population and methods. The 12 questionnaire items were translated and cross-culturally adapted using a five-step process. The construct validity was assessed using an exploratory factor analysis, whereas reliability, with Cronbach's coefficient and the G coefficient.

Results. The final questionnaire version was administered to a sample of 133 physicians who attended 9 CPD activities at a teaching hospital in the Autonomous City of Buenos Aires (average age: 38 years; $23.3 \%$, men; $76 \%$, family physicians). The exploratory factor analysis showed 3 factors (social influence, confidence in one's abilities, and ethicaljudgment). Cronbach's coefficient was 0.82 and the G coefficient, 0.72 . Conclusions. The Argentine version of the REACTION questionnaire was adapted and validated to assess the impact of CPD centered on clinical skills training on physicians' intention to implement it in their practice.

Key words: medical education, education, health care providers' attitude, surveys and questionnaires, attitude.
\end{abstract}

http: / / dx.doi.org/10.5546/ aap.2020.eng.125

This research study was conducted partially with the support of the Health Research Scholarship "Dr. Abraam Sonis," granted by the National Ministry of Health of Argentina through the Department of Health Research.

Conflict of interest:

None.

Received: 2-6-2019

Accepted: 10-17-2019 To cite: Fraguas L, Vietto V, Arceo D, Vázquez Peña F, Durante E. Adaptation and validation of the Argentine version of an instrument to assess continuing professional development activities. Arch Argent Pediatr 2020;118(2):125-129.

\section{INTRODUCTION}

There is a growing interest in the promotion of initiatives that allow knowledge translation in order to bridge the gap between the generation of scientific knowledge and the improvement of health care for the population. ${ }^{1}$ This dynamic and iterative process involves multiple actors at different levels (individual, social, and organizational): patients, investigators, educators, policymakers, and health care providers.

A component of the complex knowledge translation system is continuing professional development (CPD), which implies the acquisition and maintenance of new skills, together with a reflective practice and the consideration of contextual factors, in a practice community. ${ }^{2,3}$

The impact of CPD activities on the performance of health care providers depends, in part, on the strategies used for their design. Interactive sessions, including participatory techniques focused on the opportunity of practicing skills, promote a greater change in professional practice compared to more traditional activities, where interaction, discussion, and the implementation of new knowledge are scarce. ${ }^{4}$

In addition, the translation of new knowledge into clinical practice depends on health care providers' individual decisions, which are influenced by social and cognitive factors. Although different theoretical frameworks have been proposed that may account for professional behavior, the variables that have been identified as more relevant to predict behavior include confidence in one's abilities, beliefs about potential consequences, 
moral standards, social influences, and habits. ${ }^{5}$

These aspects were considered by a group of Canadian investigators, who developed a questionnaire to assess the intention of CPD activities participants to implement acquired skills in their own practice. ${ }^{6,7}$ The REACTION questionnaire (A theoRy-basEd instrument to assess the impACT of continuing professional development activities on professional behaviOr chaNge) is a simple, short and self-administered instrument that may provide information to facilitate quality improvement processes in CPD activities. The objective of this study was to translate and cross-culturally adapt this questionnaire for its use in Argentina, based on the original English version, and provide evidence about its validity and reliability.

\section{POPULATION AND METHOD}

The REACTION questionnaire is a multidimensional instrument made up of 12 items corresponding to 5 constructs: confidence in one's abilities, beliefs about potential consequences, moral standards, intention, and social influences. Each item in the instrument is assessed using a 7-point Likert-like scale, except for item 2, which includes 5 options. ${ }^{7}$

After obtaining the permission of the original authors, ${ }^{7}$ we translated and cross-culturally adapted the REACTION questionnaire in accordance with the step sequence described by Ramada-Rodilla. ${ }^{8}$ First, two non-licensed, bilingual translators independently translated the instrument directly into Spanish (Argentine version). After both translations were synthesized, the text was back-translated into English. Then, an expert panel made up of the participating investigators and translators gathered to obtain the pre-final, consolidated Argentine version. This version was administered in a pilot test to assess its applicability.

During the second stage, the instrument's validity was assessed in a cross-sectional, analytical study. Physicians who had been part of CPD activities centered on training a single professional skill were selected by consecutive sampling and invited to participate.

Eligible CPD activities were those that took place in person, in groups of not more than 50 participants, with learning objectives focused on behavior change, and about clinical or surgical topics. These activities had to include a single intervention, with at least $25 \%$ of interaction (considered in terms of active exchange among participants and with the trainer), with a duration of, at least, 1 hour and, at most, 3 hours. ${ }^{6}$

The following participant data were registered: sex, age, and medical specialty. The ability targeted during the training session, the scope of implementation, the duration of the activity in hours, and any educational resource used were also recorded.

The REACTION questionnaire version obtained in the first stage of this study was completed, in paper format, in an anonymous and selfadministered manner by participants, whose oral informed consent had been obtained in advance. The study was conducted between June 2017 and April 2018.

\section{Statistical analysis}

Data tabulation and descriptive statistics of the participants' demographic outcome measures were established. For continuous numerical outcome measures, the measures of central tendency and dispersion were estimated according to their distribution, whereas categorical outcome measures were described as proportions.

The questionnaire's construct validity was analyzed using an exploratory factor analysis (EFA), with the principal components technique and the Varimax rotation. Reliability was assessed using Cronbach's alpha coefficient (where a value between 0.70 and 0.90 was considered acceptable) $)^{9}$ and the generalizability $(G)$ coefficient. The PSPP and the EduG 6.1e software programs were used. A two-facet generalizability design was used: observations $(\mathrm{O})$, as a differentiation facet, and items (I), as a generalizability facet: $\mathrm{O} / \mathrm{I}$. Such design allowed to estimate the variance components of these sources, as well as the interaction between observations and items. Since $10 \%$ of questionnaires had missing data, and to provide more stability to the $\mathrm{G}$ coefficient, missing values were imputed using the mean substitution technique for valid values. ${ }^{10}$

Based on a total of 12 items included in the questionnaire, and considering that at least 10 observations were required for each item to perform the EFA, the sample size was estimated at 120 subjects. ${ }^{10}$

\section{Ethical considerations}

The protocol of this study was approved by the Research Protocol Ethics Committee of Hospital Italiano de Buenos Aires (HIBA) under protocol number 2864 . 


\section{RESULTS}

\section{Stage I: Translation and cross-cultural adaptation}

After completing the translation and crosscultural adaptation process, the Spanish, consolidated Argentine version of the questionnaire was obtained (see Annex). The pilot test was done in 25 physicians who had attended a CPD activity aimed at providing training in subdermal contraceptive implant indications and insertion. Survey respondents did not suggest any changes to the questionnaire. The reliability analysis, through the $\mathrm{G}$ coefficient, showed a value of 0.87 , with a variance of $36 \%$ among participants.

\section{Stage II: Instrument validity assessment}

The questionnaire was administered to 133 physicians who attended 9 CPD activities. Participants' average age was 38 years (standard deviation [SD]: 9). Besides, $23 \%$ were males and $76 \%$, family physicians. All activities lasted 2 hours. Different education strategies were implemented, including group discussions, clinical case discussions, role-playing, and use of manikins (Table 1).

A total of 120 complete questionnaires were included in the EFA. Although the original questionnaire ${ }^{8}$ described 5 factors, in our analysis, items were grouped into 3 factors. Cronbach's alpha coefficient was 0.827 . Table 2 shows the EFA saturations for each item and alpha's coefficients for each factor. The absolute G coefficient was 0.72 . The variance associated with the observation facet was $17.3 \%$.

\section{DISCUSSION}

This study established the translation and cross-cultural adaptation process of the REACTION questionnaire, originally developed by a team of Canadian experts on CPD and knowledge translation, and provided evidence on its validity for its use in Argentina. After administering the consolidated Argentine version of the instrument to 133 participants of 9 interactive CPD activities, it was observed that its reliability, measured based on Cronbach's alpha coefficient and the G coefficient, was adequate. In the EFA, the 12 items included in the questionnaire showed an acceptable saturation in 3 factors, called social influence, confidence in one's abilities, and ethical judgment.

In the factor that accounted for social influence, items 2, 6, and 9 showed saturation; these 3 items corresponded to the same construct in the original questionnaire. ${ }^{7}$ The confidence in one's abilities domain was represented by the items corresponding to intention (1 and 7), belief in one's abilities ( 3,5 , and 11) and one element of the moral standard construct (10) of the original questionnaire. Lastly, in relation to ethical judgment, the items about beliefs about consequences ( 8 and 12 ) and the remaining item of the moral standard construct (4) showed an adequate saturation.

Although the difference between the number of factors identified in our study and those of the original questionnaire may be considered a limitation, it is believed that item regrouping is the result of the complex theoretical framework supporting this instrument, whose repetitive nature ${ }^{11}$ may hinder the discrimination of certain constructs. The convergence of items related to intention, beliefs in one's abilities, and moral standard under the same factor may be explained by the integrated theoretical framework proposed by Godin et al., ${ }^{7}$ and may be consistent with the perceived self-efficacy concept. This term was coined by Bandura to describe a person's reliability in their ability to achieve the desired outcomes when performing a specific task, and the author claims it is a major determinant of intention. ${ }^{12}$

In addition, the convergence of items related to beliefs about consequences and moral standard under the factor called ethical judgment may

TABLE 1. Characteristics of assessed continuing professional development activities

\begin{tabular}{|c|c|c|}
\hline Activity & No. of activities & $\begin{array}{c}\text { No. of participants } \\
\text { N }(\%)\end{array}$ \\
\hline Etonogestrel subdermal implant & 3 & $50(38 \%)$ \\
\hline Levonorgestrel-releasing intrauterine system & 1 & $13(10 \%)$ \\
\hline Insulinization & 3 & $42(31 \%)$ \\
\hline Benign paroxysmal positional vertigo & 1 & $19(14 \%)$ \\
\hline Myofascial pain syndrome of the upper trapezius & 1 & $9(7 \%)$ \\
\hline
\end{tabular}


be associated with the moral principle of nonmaleficence. ${ }^{13}$ Since items 12 and 8 ask about the consideration of a behavior that is the target of a CPD activity as harmful/beneficial or useful / useless, respectively, it seems acceptable that they both showed saturation in the same factor as item 4 , which asks about considering such behavior as ethical or unethical.

The REACTION questionnaire allows to assess health care providers' intention to implement knowledge acquired in a CPD session and facilitate a reflective teaching practice. Although this is a critical step in the knowledge translation process, it is necessary to bear in mind that this instrument does not measure the actual extent of implementation in clinical practice or the quality of care received by patients.

In relation to the limitations of this study, it is worth noting that, for the validation process, the questionnaire was administered in the setting of different CPD activities offered by a single university center in the Autonomous City of Buenos Aires. It would be advisable to administer it in other continuous training settings of Argentina to document additional information about its validity in different academic environments.

Future studies would allow to broaden the range of recipients so that the questionnaire could be used in other health professions that usually require $C P D$ activities for the maintenance of clinical skills. In addition, as suggested by the instrument authors, ${ }^{10}$ it could be assessed for its implementation in other CPD activities focused on behavior change, not only on specific skills training. Also, and considering the apparent redundancy of certain items ${ }^{11}$ and the convergence of factors observed in our study, a simplified version of the questionnaire may be developed to facilitate its applicability.

\section{CONCLUSIONS}

This study allowed to obtain the Argentine version of the REACTION questionnaire to assess the impact of CPD activities centered on clinical skills training on physicians' intention to implement them in their practice.

TABLE 2. Exploratory factor analysis: saturation of the items in each factor

\begin{tabular}{|c|c|c|c|c|c|}
\hline \multirow[t]{2}{*}{ Item } & \multirow[t]{2}{*}{ Question } & \multirow[t]{2}{*}{ Original questionnaire domain } & \multicolumn{3}{|c|}{ Argentine version questionnaire domain } \\
\hline & & & $\begin{array}{l}\text { Confidence in } \\
\text { one's abilities }\end{array}$ & $\begin{array}{c}\text { Ethical } \\
\text { judgment }\end{array}$ & $\begin{array}{c}\text { Social } \\
\text { influence }\end{array}$ \\
\hline 1 & I intend to (behavior). & Intention & 0.657 & & \\
\hline 3 & $\begin{array}{l}\text { I am confident that I could } \\
\text { (behavior) if I wanted to. }\end{array}$ & Belief in one's abilities & 0.776 & & \\
\hline 5 & For me, (behavior) would be... & Belief in one's abilities & 0.616 & & \\
\hline 7 & I plan to (behavior). & Intention & 0.556 & & \\
\hline 10 & $\begin{array}{l}\text { It would be acceptable to } \\
\text { (behavior). }\end{array}$ & Moral standard & 0.515 & & \\
\hline 11 & I have the ability to (behavior). & Belief in one's abilities & 0.718 & & \\
\hline 4 & (Behavior) is the ethical thing to do. & Moral standard & & 0.629 & \\
\hline 8 & Overall, I think that (behavior) is... & Belief about consequences & & 0.865 & \\
\hline 12 & Overall, I think that (behavior) is... & Belief about consequences & & 0.844 & \\
\hline 2 & $\begin{array}{c}\text { To the best of my knowledge, } \\
\text { the percentage of my colleagues } \\
\text { who (behavior) is... }\end{array}$ & Social influence & & & 0.588 \\
\hline 6 & $\begin{array}{c}\text { Now think about a co/worker } \\
\text { whom you respect as a professional. } \\
\text { In your opinion, } \\
\text { does he/she (behavior)? }\end{array}$ & Social influence & & & 0.718 \\
\hline 9 & $\begin{array}{l}\text { Most people who are important } \\
\text { to me in my profession (behavior). }\end{array}$ & Social influence & & & 0.815 \\
\hline Cron & bach's alpha & & 0.791 & 0.715 & 0.630 \\
\hline
\end{tabular}




\section{Acknowledgments}

Fundación MF, Department of Family and Community Medicine of HIBA, Department of Gynecology of HIBA, Instituto Universitario of HIBA, Committee of Residents of HIBA, Federación Argentina de Medicina Familiar y General (Argentine Federation of Family and General Medicine, FAMFyG), Programa de Educación Continua en Salud Familiar, Ambulatoria y Comunitaria (Program for Ongoing Education on Family, Outpatient, and Community Medicine, PROFAM), Sergio Giannasi, M.D., Lorena Bozza, M.D., Rafael Pérez Vidal, M.D., Sofía Catoggio, M.D., Yamila Mahumud, M.D., Verónica Kojdamanian, M.D., Manuel Rodríguez, M.D., María José Salas, M.D., Facundo Pelorosso, M.D., Victoria Salgado, M.D., Santiago Esteban, M.D.

\section{REFERENCES}

1. Straus SE, Tetroe J, Graham ID (eds.). Knowledge Translation in heal th care: moving from evidence to practice. $2^{\text {nd }} \mathrm{ed}$. Toronto: Wiley Blackwell; 2013.

2. Davis D, Barnes BE, Fox R (eds.). The continuing professional development of physicians: from research to practice. Chicago: American Medical Association; 2003.

3. Prior Filipe H, Gwen Mack H, Golnik KC. Continuing professional development: progress beyond continuing medical education. Ann Eye Sci. 2017; 2:46.
4. Davis D, O'Brien MAT, Freemantle N, Wolf FM, et al. Impact of Formal Continuing Medical Education Do Conferences, Workshops, Rounds, and Other Traditional Continuing Education Activities Change Physician Behavior or Health Care Outcomes? JAMA. 1999; 282(9):867-74.

5. Godin G, Belanger-Gravel A, Eccles M, Grimshaw J. Healthcare professionals' intentions and behaviours: a systematic review of studies based on social cognitive theories. Implement Sci. 2008; 3:36 AM.

6. Légaré F, Borduas F, Jacques A, Laprise R, et al. Developing a theory-based instrument to assess the impact of continuing professional development activites on clinical practice: a study protocol. Implement Sci. 2011; 6:17.

7. LégaréF, Borduas F, Freitas A, Jacques A, et al. Development of a simple 12-item theory-based instrument to assess the impact of continuing professional development on clinical behavioral intentions. PloS One. 2014; 9(3):e91013.

8. Ramada-Rodilla JM, Serra-Pujadas C, Delclós-Clanchet GL. Adaptación cultural y validación de cuestionarios de salud: revisión y recomendaciones metodológicas. Salud Pública Méx. 2013; 55(1)57-66.

9. Hair J, Black W, Babin B, Anderson RE. Multivariate Data Analysis. $8^{\text {th }}$ ed. Andover: Cengage Learning EMEA; 2018.

10. Streiner D, Norman G. Biostatistics the bare essentials. $3^{\text {rd }}$ ed. New York: BC Decker; 2008.

11. Legare F, Freitas A, Turcotte S, Borduas F, et al. Responsiveness of a simple tool for assessing change in behavioral intention after continuing professional development activities. PLoS ONE. 2017; 12(5):e0176678.

12. Bandura A. Guide for constructing self-efficacy scales. In: Caprara GV (ed.). La valutazione dell 'autoeffcacia[The assessment of self-efficacy]. Trento: Erickson. 2001. Pages 15-37.

13. Beauchamp T, Childress J. Principios de Ética Biomédica. Barcelona: Masson SA; 1999. 


\section{Annex}

REACTION questionnaire for continuing professional development activities (Argentine version)

\begin{tabular}{|c|c|c|c|c|c|c|c|c|c|}
\hline 1. I intend to (behavior). & Strongly disagree & $\begin{array}{l}1 \\
\square\end{array}$ & $\begin{array}{l}2 \\
\square\end{array}$ & $\begin{array}{l}3 \\
\square\end{array}$ & $\begin{array}{l}4 \\
\square\end{array}$ & $\begin{array}{l}5 \\
\square\end{array}$ & $\begin{array}{l}6 \\
\square\end{array}$ & $\begin{array}{l}7 \\
\square\end{array}$ & Strongly agree \\
\hline $\begin{array}{l}\text { 2.To the best of my knowledge, the percentage of } \\
\text { my colleagues who (behavior) is... }\end{array}$ & $\begin{array}{c}0-20 \% \\
\square\end{array}$ & & & & & & $\begin{array}{r}61-8 \\
\square\end{array}$ & & $\begin{array}{c}81-100 \% \\
\square\end{array}$ \\
\hline $\begin{array}{l}\text { 3. I am confident that I could (behavior) if I } \\
\text { wanted to. }\end{array}$ & Strongly disagree & $\begin{array}{l}1 \\
\square\end{array}$ & $\begin{array}{l}2 \\
\square\end{array}$ & $\begin{array}{l}3 \\
\square\end{array}$ & $\begin{array}{l}4 \\
\square\end{array}$ & $\begin{array}{l}5 \\
\square\end{array}$ & $\begin{array}{l}6 \\
\square\end{array}$ & $\begin{array}{l}7 \\
\square\end{array}$ & Strongly agree \\
\hline 4. (Behavior) is the ethical thing to do. & Strongly disagree & $\begin{array}{l}1 \\
\square\end{array}$ & $\begin{array}{l}2 \\
\square\end{array}$ & $\begin{array}{l}3 \\
\square\end{array}$ & $\begin{array}{l}4 \\
\square\end{array}$ & $\begin{array}{l}5 \\
\square\end{array}$ & $\begin{array}{l}6 \\
\square\end{array}$ & $\begin{array}{l}7 \\
\square\end{array}$ & Strongly agree \\
\hline 5. For me, (behavior) would be... & Extremely difficult & 1 & $\begin{array}{l}2 \\
\square\end{array}$ & $\begin{array}{l}3 \\
\square\end{array}$ & $\begin{array}{l}4 \\
\square\end{array}$ & $\begin{array}{l}5 \\
\square\end{array}$ & $\begin{array}{l}6 \\
\square\end{array}$ & $\begin{array}{l}7 \\
\square\end{array}$ & Extremely easy \\
\hline $\begin{array}{l}\text { 6. Now think about a co-worker whom you } \\
\text { respect as a professional. In your opinion, } \\
\text { does he/she (behavior)? }\end{array}$ & Never & $\begin{array}{c}1 \\
\square\end{array}$ & $\begin{array}{l}2 \\
\square\end{array}$ & $\begin{array}{l}3 \\
\square\end{array}$ & $\begin{array}{l}4 \\
\square\end{array}$ & $\begin{array}{l}5 \\
\square\end{array}$ & $\begin{array}{l}6 \\
\square\end{array}$ & $\begin{array}{l}7 \\
\square\end{array}$ & Always \\
\hline 7. I plan to (behavior). & Strongly disagree & 1 & $\begin{array}{l}2 \\
\square\end{array}$ & $\begin{array}{l}3 \\
\square\end{array}$ & $\begin{array}{l}4 \\
\end{array}$ & $\begin{array}{l}5 \\
\square\end{array}$ & $\begin{array}{l}6 \\
\square\end{array}$ & $\begin{array}{l}7 \\
\square\end{array}$ & Strongly agree \\
\hline 8. Overall, I think that (behavior) is... & Useless & $\begin{array}{l}1 \\
\square\end{array}$ & $\begin{array}{l}2 \\
\square\end{array}$ & $\begin{array}{l}3 \\
\square\end{array}$ & $\begin{array}{l}4 \\
\square\end{array}$ & $\begin{array}{l}5 \\
\square\end{array}$ & $\begin{array}{l}6 \\
\square\end{array}$ & $\begin{array}{l}7 \\
\square\end{array}$ & Useful \\
\hline $\begin{array}{l}\text { 9. Most people who are important to me in my } \\
\text { profession (behavior). }\end{array}$ & Strongly disagree & $\begin{array}{l}1 \\
\square\end{array}$ & $\begin{array}{l}2 \\
\square\end{array}$ & $\begin{array}{l}3 \\
\square\end{array}$ & $\begin{array}{l}4 \\
\square\end{array}$ & $\begin{array}{l}5 \\
\square\end{array}$ & $\begin{array}{l}6 \\
\square\end{array}$ & $\begin{array}{l}7 \\
\square\end{array}$ & Strongly agree \\
\hline 10. It would be acceptable to (behavior). & Strongly disagree & 1 & $\begin{array}{l}2 \\
\square\end{array}$ & $\begin{array}{l}3 \\
\square\end{array}$ & $\begin{array}{l}4 \\
\square\end{array}$ & $\begin{array}{l}5 \\
\square\end{array}$ & $\begin{array}{l}6 \\
\square\end{array}$ & $\begin{array}{l}7 \\
\square\end{array}$ & Strongly agree \\
\hline 11. I have the ability to (behavior). & Strongly disagree & $\begin{array}{l}1 \\
\square\end{array}$ & $\begin{array}{l}2 \\
\square\end{array}$ & $\begin{array}{l}3 \\
\square\end{array}$ & $\begin{array}{l}4 \\
\square\end{array}$ & $\begin{array}{l}5 \\
\square\end{array}$ & $\begin{array}{l}6 \\
\square\end{array}$ & $\begin{array}{l}7 \\
\square\end{array}$ & Strongly agree \\
\hline 12. Overall, I think that (behavior) is... & Harmful & $\begin{array}{l}1 \\
\square\end{array}$ & $\begin{array}{l}2 \\
\square\end{array}$ & $\begin{array}{l}3 \\
\square\end{array}$ & $\begin{array}{l}4 \\
\square\end{array}$ & $\begin{array}{l}5 \\
\square\end{array}$ & $\begin{array}{l}6 \\
\square\end{array}$ & $\begin{array}{l}7 \\
\square\end{array}$ & Beneficial \\
\hline
\end{tabular}

